\title{
"Meninas": os conflitos com a lei e as representações das medidas socioeducativas
}

\section{"Girls": Conflicts with the law and representations of social-educational measures}

\author{
Alexandre Cardoso Aranzedo ${ }^{1}$
}

\begin{abstract}
RESUMO: No Brasil tem sido crescente o envolvimento das adolescentes em atos infracionais, o que tem despertado o interesse acadêmico. O presente estudo visa analisar os fatores que contribuem para o envolvimento de meninas na prática de delitos e investigar como estas representam a medida socioeducativa (MSE) de Liberdade Assistida (LA) e Internação. O método preconizou a participação de adolescentes do sexo feminino que cumpriam MSE de Internação e LA. Os resultados demonstram que os delitos se concentram no tráfico de drogas, assaltos, lesões corporais e furtos. As representações das MSE de LA, partilhadas pelas adolescentes, caracterizam-na como um espaço de aprendizagem (reflexivo). Sobre a internação, algumas retratam também como um espaço de aprendizagem, mas, sobretudo, como punição e solidão.
\end{abstract}

Palavras-chave: adolescentes; representações sociais; adolescente em conflito com a lei; medidas socioeducativas.

\begin{abstract}
In Brazil, the increasing involvement of female adolescents in criminal activities awakens academic interest. The present study aims to analyze the factors that contribute to the involvement of girls in criminal activities, as well as to investigate how those girls represent the Social-educational Measure of Internment and Assisted Freedom. Research method elected as subject female adolescents that were either under the Social-educational Measure of Internment or Assisted Freedom. Results show that the criminal activities in which the subjects were involved concentrate on drug trafficking, robbery and physical injuries. Representations of the Socialeducational Measure of Assisted Freedom shared among the adolescents were characterized as a learning environment (reflexive). Some of them represented Internment as a learning environment, but also as punishment and loneliness.
\end{abstract}

Keywords: gender; adolescents; social representations; adolescents in conflict with the law; social educational measures.

\section{Introdução}

Ao longo das últimas décadas, verificam-se no campo da Psicologia e demais ciências sociais, mudanças nos paradigmas vigentes nos estudos sobre adolescência. Nos dias atuais, sobretudo nos estudos de Psicologia Social, observa-se a ampliação de investigações sobre adolescentes e suas práticas tendo como parâmetro os aspectos econômicos, sociais, culturais, étnicos e de gênero (Menandro, Trindade \& Almeida, 2003). Nesse sentido, o envolvimento de adolescentes em atos infracionais tem despertado o interesse da comunidade acadêmica e da sociedade em geral, visto que tais práticas não são aceitas socialmente, embora sejam produzidas a partir do entrelaçamento de vários processos construídos pela sociedade brasileira.

A inserção de adolescentes nos atos infracionais pode ser ocasionada por diversos fatores, tais como: mudanças no padrão civilizatório, esvaziamento de sentido nas relações humanas, falta de perspectivas de futuro, insegurança, imposições do consumo,

\footnotetext{
${ }^{1}$ Doutor em Psicologia; Coordenador e Docente do Curso de Psicologia da Faculdade Católica Salesiana do Espírito Santo Vitória, ES, Brasil. E-mail: aaranzedo@catolica-es.edu.br.
} 
necessidades de sobrevivência, prevalência de transtornos mentais, uso de drogas lícitas e ilícitas, violência doméstica, influência da família e de colegas/ amigos, busca por signos do poder, desterritorialização comunitária, desigualdade social, desemprego, problemas habitacionais, sedução pela vida do crime, ostentação, busca pelo poder de consumo entre outros (Agliardi, 2007; Sanabria \& Rodrigues, 2010; Zappe \& Ramos, 2010; Gomes \& Conceição, 2014; Silva, 2014).

Grande parte das investigações sobre conflito com a lei produz resultados, baseados no estudo de adolescentes do sexo masculino, visto que eles representam o maior contingente populacional desse segmento. Essa realidade pode favorecer a inobservância das singularidades presentes nas histórias do envolvimento das "meninas" nos atos infracionais. Por consequência, os dados coletados junto aos adolescentes do sexo masculino, se generalizados, podem mascarar ou masculinizar esse complexo fenômeno social.

No intuito de compreender o ingresso de meninas nos atos infracionais, pesquisas identificaram os seguintes fatores contributivos: relacionamentos amorosos com pessoas vinculadas à criminalidade; admiração do comportamento masculino; necessidades de consumo; ostentação; vitimização por violência; rupturas de vínculos afetivos; uso de drogas; laços familiares fragilizados; sensação de pertencimento ao grupo de pares; pobreza; e reconhecimento social (Almeida, 2007; Dell'aglio, Santos \& Borges, 2004; Fachinetto, 2008; Monteiro et al., 2011; Silva 2014).

Entre os referenciais adotados, a Teoria das Representações Sociais (TRS) tem sido uma das relevantes abordagens teóricas utilizados para investigar o tema dos adolescentes em conflito com a lei, visto que este aporte possibilita desvelar o modo como os sujeitos produzem, representam sua realidade, norteiam e justificam suas práticas (Abric, 2001; Moscovici, 2004). As representações sociais (RS) podem ser conceituadas como “... uma forma de conhecimento, socialmente elaborada e partilhada, com um objetivo prático, e que contribui para a construção de uma realidade comum a um conjunto social" (Jodelet, 2001, p. 22). Os processos formadores das RS são a objetivação e a ancoragem. Segundo Jovchelovitch (2003, p. 81),

\begin{abstract}
A objetivação e ancoragem são as formas especificas em que as representações sociais estabelecem mediações, trazendo para um nível quase material a produção simbólica de uma comunidade e dando conta da concretude das representações sociais na vida social. De certa forma, eles podem ser enriquecidos se comparados aos processos de condensação e deslocamento que discutimos antes. Objetivar é também condensar significados diferentes significados que frequentemente ameaçam, significados indizíveis, inescutáveis - em uma realidade familiar. Ao assim o fazer, sujeitos sociais ancoram o desconhecido em uma realidade conhecida e institucionalizada e, paradoxalmente, deslocam aquela geografia de significados já estabelecida, que as sociedades, na maior parte das vezes, lutam para manter. As representações sociais emergem desse modo como processo que ao mesmo tempo desafia e reproduz, repete e supera, que é formado, mas que também forma a vida social de uma comunidade.
\end{abstract}

A partir dessa perspectiva teórica, o presente trabalho visou analisar os fatores que contribuem para o envolvimento de meninas na prática de atos infracionais, e ainda investigar como as adolescentes representavam as medidas socioeducativas (MSE) de Internação e Liberdade Assistida (LA). 


\section{Método}

\section{Participantes}

Do presente estudo participaram 20 (vinte) adolescentes do sexo feminino, de 13 a 19 anos, que estiveram em conflito com a lei e que cumpriam MSE de liberdade assistida (10 meninas) ou estavam acauteladas em unidade de internação (10 meninas). Grande parte das adolescentes se identificava como pardas e negras. Os dados sobre escolaridade demonstram que 1 (uma) adolescente concluiu o ensino fundamental e 14 (quatorze) adolescentes estudaram até a $3^{\text {a }}$ série (1); 5 a série (5); 6a série (3) e 7ạ série (5). Entre as cinco que cursaram o nível médio de ensino, nenhuma o concluiu.

\section{Campo de estudo}

O estudo foi realizado em dois campos: Unidade Feminina de Internação (UFI) do Estado do Espírito Santo, unidade de internação gerida pelo Instituto de Atendimento Socioeducativo do Espírito Santo (IASES); e serviços de execução da medida socioeducativa de liberdade assistida dos Centros de Referência Especializados de Assistência Social (CREAS) de Vitória-ES.

\section{Instrumento de coleta de dados}

A coleta de dados consistiu na realização de entrevista individual, norteada por roteiro semiestruturado e instrumento indutor que pesquisou o envolvimento de meninas na prática de atos infracionais e suas avaliações das medidas socioeducativas de Internação e Liberdade Assistida (LA).

\section{Aspectos éticos da pesquisa}

Os preceitos éticos foram observados no decorrer do desenvolvimento da pesquisa, assegurando às participantes o direito da participação voluntária, confidencialidade, anonimato de todas as informações coletadas, possibilidade de se recusar a participar da pesquisa em qualquer etapa. Todos os nomes mencionados nos extratos das entrevistas são fictícios.

\section{Análise e interpretação de dados}

Os dados obtidos foram analisados por meio da técnica de análise temática do conteúdo sistematizada por Bardin (1977), utilizando-se como aporte teórico a Teoria das Representações Sociais.

\section{Resultados e discussão}

Ao analisar a participação das adolescentes pesquisadas nos atos infracionais, observase que os delitos cometidos se concentram no tráfico de drogas (16), na prática de assaltos 
(5), no cometimento de lesões corporais (2) e na realização de furtos (2). Ressalta-se que algumas cometeram mais de um tido de delito.

Guardadas as devidas proporções, o envolvimento das adolescentes com atos infracionais apresenta algumas características semelhantes às encontradas na inserção das mulheres adultas. Ao longo das últimas décadas, observa-se que o envolvimento feminino no tráfico de drogas tem sido um fator preponderante para o incremento das taxas de aprisionamento de mulheres (Barcinski, 2009).

No caso das adolescentes, observamos graus de envolvimentos diferenciados com o tráfico de drogas. Em alguns casos, se considerarmos somente o volume de drogas apreendidas sob a responsabilidade das adolescentes, poderemos ter uma noção mais clara de como as adolescentes estão envolvidas, conforme podemos observar na história de Patrícia, 17 anos: "Eu fui presa com 7 quilos de maconha, 200 gramas de pó [cocaína], $400 \mathrm{~g}$ de pedra [crack], um oitão, 15 munições e três mil e pouco em dinheiro ..." (Patrícia, 17 anos, Unidade Feminina de Internação).

A participação das meninas no tráfico de drogas estende-se a quase todas as atividades desenvolvidas pelas quadrilhas organizadas, tais como a preparação da droga para a venda (função de enrolamento ou 'endolamento'), comercialização dos produtos (função de vapor), vigilância dos pontos de venda e fabricação (função de olheiro), transporte de drogas (função de 'aviãozinho', 'mula' ou 'bonde'), gerência da boca de fumo (gestão local de todas as atividades do tráfico) e associação com o tráfico (proximidade acentuada com pessoas envolvidas no narcotráfico).

Outro delito presente na história das entrevistadas é a realização de crimes contra o patrimônio, furtos e assaltos, como se observa na história de Aparecida, 17 anos, apreendida pela prática de assalto: “... vinha uma menina e um menino, falamo vai ser aqueles. Fomos assaltamo, pegamos o celular dos dois. [...] Nós falamo que tava armado, eles acredita. Terror psicológico ..." (Aparecida, 17 anos, Unidade Feminina de Internação).

Os roubos e furtos figuram como a segunda causa do encarceramento de mulheres no Rio de Janeiro, e como o principal crime praticados por homens (Carvalho, Valente, Assis \& Vasconcelos, 2006). No estudo de adolescentes autores de ato infracional, do sexo masculino, Zappe e Ramos (2010) verificaram que os meninos também são apreendidos, na maioria das vezes, pela prática de assaltos. Nesses casos, os autores acentuam a preponderância dos fatores socioeconômicos e dos valores capitalistas e consumistas como motivadores desses delitos.

No caso das adolescentes pesquisadas, observa-se ainda a ocorrência do delito de lesões corporais. Embora seja menos frequente, esse tipo de delito impressiona pelo grau de violência empregada, conforme retrata Tatiana, 15 anos:

... entrei numa briga com uma vizinha minha e a filha dela. Eu já morava em Cariacica. Eu rasguei a cara dela e da filha dela com uma corrente. Rasguei mesmo, abriu com a corrente [...] Eu fui sem dó, nem piedade com a corrente na cara delas e comecei a surra de corrente, só na cara. Aí abriu, sei que abriu. Elas levaram ponto, o rosto delas ficou feio. A mulher tinha 35 anos e a menina dela tinha 18. Eu peguei as duas (Tatiana, 15 anos, Liberdade Assistida).

A participação de meninas em atos violentos como a lesão corporal impressiona, pois se configura como uma ação que, de certa forma, contraria os sentidos e atributos de gênero produzidos socialmente para as mulheres. Ao longo da história, as relações sociais estabelecidas entre homens e mulheres na sociedade brasileira produziram um panorama 
de significados sobre as mulheres, caracterizadas ao longo desse processo pela passividade, domínio do espaço doméstico, boa educação, bons costumes, dupla jornada de trabalho, beleza e sensualidade (Madureira, 2010). Por isso, os atos violentos cometidos pelas adolescentes frequentemente causam certa repulsa por boa parte da sociedade, já que estes não são esperados e são socialmente inaceitáveis, principalmente se praticados por mulheres e meninas.

A mulher quando pratica ações violentas sofre uma dupla discriminação pelo ato cometido, tanto no âmbito das relações sociais cotidianas, quanto na vivência no contexto prisional. No âmbito do sistema prisional feminino a vitimização por violência e o sofrimento por maus tratos podem se agravar em função do tipo de delito cometido. Uma mulher aprisionada pelo cometimento de infanticídio poderá sofrer, de forma violenta, as consequências do ato cometido (Sánchez, 2002).

A partir da perspectiva das adolescentes, observa-se que a obtenção de visibilidade social, por meio do exercício do poder, alcance da fama e ganhos financeiros que viabilizam o consumo, têm sido fatores preponderantes no envolvimento de meninas nos atos infracionais, principalmente no tráfico de drogas, conforme relata Penha, 19 anos: “... muitas fazem por prazer, pra se sentir a maioral, a 'fodona', já que antes era excluída [...] Muitas influenciada pelos traficantes, ficam deslumbradas, porque elas são poderosas ..." (Penha, 19 anos, Liberdade Assistida).

Ao se vincular ao tráfico de drogas as mulheres rompem com o espaço social privado, sobretudo doméstico, e passam a experimentar o domínio do espaço público, por meio do exercício do poder, do consumo e da obtenção de fama, principais motivadores para a inserção nessa atividade (Barcinski, 2009; Souza, 2009).

Na perspectiva das entrevistadas, o modo como o tráfico de drogas é representado socialmente se diferencia bastante do modo como o poder público e o discurso de especialistas da segurança pública o concebem. A partir de pressupostos da TRS, supõe-se que no discurso oficial (universos reificados) o tráfico de drogas se constitui numa atividade criminosa que contraria as normas sociais vigentes, a qual as ações advindas das políticas de enfrentamento ao narcotráfico devem erradicar.

Amparada em lastros morais, escorando-se também em saberes médico-sanitários, a luta contra o narcotráfico é acionada politicamente quando o próprio tráfico de drogas é içado ao posto de maior antígeno a "infectar" e "corromper" a vida social e institucional dos Estados neodemocráticos. O narcotráfico, considerado o amálgama que congrega e patrocina diversas manifestações da criminalidade organizada, passa a ser alvo de Estados que não discutem tão só a internacionalização de suas economias, mas que investem no enrijecimento harmônico das políticas de repressão à produção, tráfico e consumo de drogas (Rodrigues, 2002, p. 102).

Por outro lado, observa-se que para as meninas em conflito com a lei, e supostamente outros adolescentes, o tráfico de drogas e outros delitos vinculados, representam uma forma de obtenção de status, fama, poder e dinheiro, o que torna o envolvimento com a prática de delitos uma possibilidade de vida.

Ao analisar a ancoragem, um dos processos fundamentais de formação das representações sociais (RS), observa-se que as imagens construídas por traficantes de drogas, como pessoas detentoras de status e poder, encontram-se ancoradas nas RS de 
"heróis" e "anti-heróis", possibilitando que os integrantes do tráfico de drogas sejam admirados, invejados, temidos e se tornem padrões de referência de vida para várias pessoas, principalmente nas comunidades em que vivem.

Outro aspecto a ser considerado para a compreensão do envolvimento de meninas com atos infracionais é a vivência de conflitos familiares e/ou a influência da família. Apesar de ser esperado que a família seja um dos principais fatores de proteção para os adolescentes, observa-se que em alguns casos dos que cometeram atos infracionais esta passa ser culpabilizada, por parte da sociedade, como uma instância que falhou no processo educativo, o que proporciona que seja vista como parte do 'problema' e não da solução (Costa, 2006; Zappe \& Dias, 2012). Os conflitos intrafamiliares decorrem, sobretudo, de questões relacionadas ao exercício da autoridade e/ ou do estabelecimento de uma relação conflituosa com as mães (Almeida, 2007; Nardi \& Dell'Aglio, 2012).

O envolvimento de meninas com a criminalidade também ocorre a partir do estabelecimento de relações afetivas (amizade, namoro, casamento) com pessoas vinculadas ao tráfico de drogas, conforme relatado por Gizele, 18 anos: "Tem meninas que entram nessa vida por causa de homem ..." (Gizele, 18 anos, Liberdade Assistida).

As mulheres se relacionam afetivamente com homens participantes de atividade criminosas principalmente por necessidade financeira ou com a finalidade de obter reconhecimento, poder social e econômico (Ireland \& Lucena, 2013). A partir desse envolvimento as mulheres passam a ter acesso a todos os procedimentos relacionados à prática criminosa, tornando-se cúmplices, e às vezes, participando das operações previstas (Barcinski, 2009; Lago, 2014). Entretanto, em algumas situações, as mulheres (namoradas, esposas, companheiras),

...descobrem posteriormente que seus parceiros estão envolvidos em atividades criminosas e, frequentemente, não têm opção a não ser servir de cúmplices para seus crimes. A "mulher de bandido", assim como a "fiel" (aquela mulher que deve permanecer fiel ao companheiro encarcerado) são submetidas às regras informais que regem as relações entre homens e mulheres no tráfico de drogas (Barcinski, 2009, p. 1848).

No ingresso das meninas no tráfico de drogas, verificou-se que os vínculos de amizade com traficantes contribuem de forma significativa para esse delito, conforme relata Valéria, 19 anos (Unidade Feminina de Internação): “... aí eu fui me enturmando com gente que não presta. Foi o ponto que eu comecei a traficar, comecei a roubar, ao ponto que eu cheguei aqui ...". Vale lembrar que nem sempre o vínculo de amizade com pessoas ligadas à criminalidade provoca o envolvimento na prática de delitos. "Pertencer a uma gangue é buscar um lugar e posição, significa estar inserido num jogo de rivalidades; é a procura da identidade social no âmbito de uma cultura, na qual esses grupos podem ou não conduzir-se à delinquência" (Feffermann, 2006, p. 195).

Embora seja controversa, a pobreza tem sido um dos fatores apontados para se compreender a inserção das adolescentes nos atos infracionais, conforme relatado por Patrícia, 17 anos (Unidade Feminina de Internação): ... tem meninas que entram por necessidade [...] Umas precisam de dinheiro pra se sustentar. Que nem uma das internas que tá ali que é moradora de rua ...". De acordo com Barcinski (2009, p. 1847),

entender o ingresso de jovens - homens e mulheres - no tráfico de drogas como consequência de dificuldades econômicas e como alternativa à inserção no mercado formal de trabalho parece não trazer grandes novidades. Apesar de refletir em parte a realidade desses jovens, tal justificativa não deve ser adotada sem ressalvas, uma vez que ela pode implicar um 
determinismo social problemático. Determinismo que reproduz os discursos segundo os quais a pobreza e a exclusão social levam, invariavelmente, à criminalidade e à delinquência.

Outros aspectos a serem considerados, na inserção das adolescentes na criminalidade, são a sensação de impunidade e pouca capacidade de avaliar as consequências dos atos que estão sendo cometidos, conforme exemplifica Luana, 18 anos, Liberdade Assistida “... naquela hora ali eu não queria saber de nada! A mesma coisa que um homem faz ela quer fazer também, não pensa e quando vai ver está atrás das grades...". A falta de “... alternativas concretas, que lhe permitam viabilizar-se como pessoa, trabalhador e cidadão, acaba levando o adolescente a murar-se no imediatismo, esse insaciável devorador de horizontes, e na inconsequência, a sua irmã siamesa" (Costa, 2006, p. 25).

O comportamento inconsequente de algumas adolescentes, associado ao desejo de viver aventuras, contribui para que "escolham" o envolvimento nos delitos, conforme relata Aparecida, 17 anos, Unidade Feminina de Internação: "É por opção de vida. Querer experimentar essa vida do mundão, do tráfico. Como é usar droga, como é correr da polícia, enfrentar bandido". O desejo de viver aventuras, situações desafiadoras, apresenta-se como uma característica comum a vários jovens, levando-os a vivenciar situações de risco, que são bastante presentes na atuação no tráfico de drogas (Feffermann, 2006).

No decorrer da pesquisa, também se abordou junto às adolescentes como elas representavam as medidas socioeducativas (MSE) de Liberdade Assistida (meio aberto) e de Internação (privativa de liberdade). Ressalta-se que algumas das adolescentes já vivenciaram as duas realidades socioeducativas.

No que tange à medida de liberdade assistida (LA), os dados obtidos demonstram que grande parte das adolescentes a representa como um espaço de aprendizagem (pedagógico, reflexivo, de mudança de comportamentos). Mas, algumas a representam, a partir das dificuldades vivenciadas na medida de LA.

Ao representar a MSE de LA com atributos de um espaço de aprendizagem, as adolescentes evidenciam sua dimensão sociopedagógica promotora de ações que possibilitem o acompanhamento técnico especializado (Psicólogos, Assistentes Sociais, Pedagogos, Educadores e Oficineiros), a fim de fomentar reflexão, ressignificação do ato infracional realizado e desejo de mudança de comportamentos, conforme relata Luana, 18 anos, Liberdade Assistida, a MSE de LA representa " Uma reflexão para mim, de tudo que eu passei e para não voltar a fazer mais. Todos aqui pensam no nosso melhor, sempre tentando da melhor forma ajudar e querendo que a gente cresça a partir daqui". O mesmo aspecto tem sido ressaltado por Gizele, 18 anos, liberdade assistida:

\begin{abstract}
... aqui tem educadoras pra ensinar o que é certo e o que é errado, aqui tem pessoas que dá para se espelhar como exemplo, é legal. É por isso, por mais que eu pense em voltar pro tráfico, eu paro e olho exemplos daqui de pessoas que não tiveram condições, mas que estudaram, fizeram faculdade, são bolsistas. Eu olho e penso, se eles conseguiram, porque eu também não posso conseguir. Eles tiveram dificuldades mais ou menos do que eu. Ás vezes eu penso sim em voltar pro tráfico. Mas, por causa daqui eu não volto. Esse lugar aqui é o melhor de mim. Quando eu sair daqui eu vou continuar vindo. Se não fosse as pessoas daqui, eu acho que continuaria a ser uma adolescente rebelde.
\end{abstract}

A representação da MSE de LA como um espaço de aprendizagem e mudança também foi observado por Coelho e Rosa (2013) e pode evidenciar o cumprimento de alguns dos preceitos legais do ECA e das diretrizes do Sistema Nacional de Atendimento Socioeducativo (SINASE) - parâmetro jurídico, pedagógico, político, administrativo e financeiro - que 
estabelece as competências, princípios e diretrizes pedagógicas para a execução do atendimento socioeducativo aos adolescentes em conflito com a lei. O ECA e o SINASE indicam a prioridade de aplicação das medidas em meio aberto (LA ou Prestação de Serviços à Comunidade - PSC), em detrimento das medidas restritivas de liberdade, visto que as medidas em meio aberto tornam possível uma interação constante entre adolescentes, famílias e comunidades, aspectos relevantes nos processos socioeducativos dos adolescentes (Conselho Nacional dos Direitos da Criança e do Adolescente, 2006).

A promoção da integração do adolescente com sua família e comunidade torna-se imprescindível para uma execução eficaz da LA e, para isso, torna-se necessário o estabelecimento de uma ampla rede de atendimento integral às famílias a partir do acesso às políticas públicas e iniciativas comunitárias (Brito, 2007).

Ao representar a LA a partir das dificuldades vivenciadas na medida socioeducativa, as adolescentes evidenciam as dificuldades em se afastar da prática de atos infracionais, em se vincular às escolas, em obter trabalho e ter disciplina para cumprir a MSE, conforme se observa na história de Gizele, 18 anos, liberdade assistida:

... na minha família eu não vejo essa ajuda. Pra mim minha mãe não me conhece. Tipo lá em casa, eu não tenho o carinho da minha mãe, é muito estranho. Eu tô desanimada com a escola, era pra eu buscar uma declaração, mas eu nem busquei. Um pouco de falta de interesse, entendeu. Tá difícil ficar sem voltar pra vida do crime, tá muito difícil, tá complicado, porque tipo falta de dinheiro. Mas, isso é o de menos. Porque, às vezes as pessoas irritam tanto a gente, tanto a gente que a gente pensa em mil coisas. Às vezes em casa, minha mãe briga comigo porque eu nunca tenho dinheiro pra isso, praquilo ...

As dificuldades observadas na história de algumas adolescentes em LA não são situações pontuais. No Brasil, uma série de dificuldades é observada na execução das medidas em meio aberto, tais como: ausência de tratamento de toxicômanos; impedimento na matrícula escolar; defasagem entre idade e série; desinteresse e/ou resistência do adolescente em seguir as recomendações da justiça; falta de espaços de lazer, esporte e cultura; e pouca inserção no mercado de trabalho (Ferreira, 2006).

Outra crítica que se coloca, mesmo considerando os avanços do ECA e a significativa contribuição dos serviços de liberdade assistida, é que,

a L.A. em sua proposta de atuação, pretende a "reinclusão" do adolescente autor de ato infracional via escola, trabalho, profissionalização e reflexão (leia-se "conscientização") sobre seus atos. Entretanto, fica patente que a L.A. não vai reincluí-lo. Primeiro, porque na verdade nunca foram incluídos de outro modo que não pela exclusão. Segundo, porque a L.A. continua reproduzindo mitos da sociedade capitalista e que traduzem os interesses ideológicos da classe dominante. $E$, terceiro, porque a reflexão sobre seus atos torna-se um discurso vazio se não houver a reflexão crítica a respeito de sua própria condição social e histórica (Cabral, 2003, p. 111).

No que tange à medida socioeducativa de Internação verifica-se que algumas adolescentes a representam como um espaço de aprendizagem (pedagógico, reflexivo, de aprendizado), mas, sobretudo, como espaço de punição, solidão ou carência afetiva.

Ao representar a MSE de Internação com características vinculadas a um espaço de aprendizagem, as adolescentes a caracterizam como aspecto pedagógico; atendimento especializado (Psicólogos, Assistentes Sociais, Assessor Jurídico); alimentação; higiene; profissionalização; disciplina; e como possibilidade de responsabilização, reflexão, amadurecimento e aprendizado. 
O aspecto reflexivo evidenciado por algumas das adolescentes em relação à medida socioeducativa de Internação, contraria os principais resultados encontrados por Braunstein (2007), entre mulheres do sistema prisional e por Aranzedo e Souza (2007) com adolescentes do sexo masculino. O estudo de Braunstein (2007) demonstra a ausência de espaços de reflexão, de estudos, de práticas religiosas e de contato com as famílias. $\mathrm{Na}$ investigação de Aranzedo e Souza (2007) observou-se a preponderância de aspectos negativos na MSE de Internação, caracterizada pela ociosidade, tratamento inadequado e ineficácia de um projeto pedagógico que direcionasse as atividades realizadas.

A partir disso, podemos inferir que, de certa forma, a MSE de Internação para as meninas pesquisadas pauta-se numa lógica um pouco diferente daquela aplicada à internação de meninos, o que tem promovido a possibilidade de algumas refletirem sobre suas vidas, a despeito das condições precárias do espaço físico de execução dessa MSE no Estado do Espírito Santo.

Ressalta-se que o Conselho Nacional de Justiça (CNJ) recomendou o fechamento da Unidade Feminina de Internação (UFI), a partir de inspeção realizada em 2013, onde evidenciou-se a péssima estrutura física da unidade, escassez de recursos e utilização de conteiners como espaços físicos nas áreas administrativas e de atendimento às adolescentes (Conselho Nacional de Justiça, 2013).

Nesse sentido um número significativo de adolescentes representa a MSE de Internação, sobretudo como espaço de punição, cujos elementos representacionais são: "ruim", "constrangedor", "ineficaz", "injusto" e que favorece o aprendizado de "comportamentos inadequados", conforme descrito por Valéria, 15 anos, Unidade de Internação: “... não vai me recuperar assim, não vai me fazer refletir. Eu acho que cadeia, não vai melhorar em nada, a pessoa só vai piorando cada vez mais. Porque eu sei, porque a gente fica trancada como a gente se fosse um bicho".

As representações negativas da MSE de Internação decorrem do modelo vigente de execução de medidas socioeducativas de Internação no Brasil, no qual se incorpora uma intervenção de doutrinação, onde o adolescente,

\footnotetext{
... há de se transformar. Há de mudar o seu ponto de vista. Há de incorporar valores. Há de se tornar menos impulsivo, menos agressivo, mais tolerante à frustração. Há de assumir sua culpa, implicar-se em sua ação, não minimizar sua responsabilidade, não atribuí-la ao influxo de terceiros. Há de chorar pela vítima, há de se por no lugar dela, há de sentir culpa, há de admitir culpa. Há de aceitar justa, pelo que fez, a privação de liberdade imposta. Há de submeter-se, dócil, às privações de liberdade e heteronomia do cotidiano. Há de interessar-se pela escola, aproveitar a profissionalização e manter-se distante das lideranças negativas (Frasseto, 2006, p. 320).
}

Uma questão que se coloca, no caso da internação de meninas é que a maioria das ações propostas pelo poder público visa que as adolescentes internalizem "... um modelo de mulher distinto daquele que elas construíram na socialização primária. Um modelo que seja socialmente aceito, que direcione a mulher para o âmbito doméstico e privado da vida" (Fachinettto, 2008, p. 213). Aspecto que, nos dias atuais, pode não ser tão bem aceito pelas meninas, considerando os avanços que as mulheres têm obtido na sociedade brasileira.

O sentimento de solidão/ carência afetiva, como a principal representação da MSE de internação, para algumas adolescentes, demonstra o afastamento da família durante o cumprimento da medida, uma vez que o contato com a família é limitado, constrangedor e restrito a visitas semanais, conforme relata Valéria, 15 anos: “... porque pra mim, aqui é um 
lugar que filha chora e mãe não vê. Quem inventou as grade não sabe a dor da saudade que a gente sente da família ..." (Valéria, 15 anos, Unidade Feminina de Internação).

\section{Conclusões}

Ao analisar os fatores que contribuem para o envolvimento de meninas na prática de atos infracionais a partir da perspectiva das adolescentes pesquisadas verificamos a relevância dos seguintes aspectos: obtenção da visibilidade social (poder, fama, consumismo); conflitos e influência de familiares e relacionamentos afetivos com pessoas ligadas à criminalidade.

A necessidade de obter visibilidade social, por meio do exercício do poder, alcance da fama e ganhos financeiros que viabilizam o consumo imediato, tem favorecido a vinculação de meninas com a prática de atos infracionais, sobretudo no narcotráfico, uma vez que para as adolescentes pesquisadas, e, talvez para outros grupos que vivenciam situações de vulnerabilidade, o tráfico de drogas apresenta elementos que favorecem a visibilidade social. Apesar disto, devemos ressaltar que não são todas as meninas que, ao se inserirem no tráfico, obtêm a visibilidade e ascensão social esperada. Algumas conseguem obter certo poder, mas ainda são obrigadas a se assujeitar ao poder e aos desejos de homens vinculados à criminalidade.

No que concerne à aplicação das medidas socioeducativas, observamos que boa parte das meninas recebe medida socioeducativa em meio aberto, em detrimento da privativa de liberdade. Frequentemente, as adolescentes cumprem o acautelamento provisório nas unidades de internação e, posteriormente, recebem medida de liberdade assistida ou prestação de serviços à comunidade. Acreditamos que isto ocorre devido à forma como, comumente, as mulheres e as adolescentes são representadas socialmente, que as afasta de certa "periculosidade", característica atribuída a homens (adolescentes, jovens ou adultos) que cometem delitos, o que pode influenciar nas decisões do judiciário.

Tal aspecto também foi observado em estudos realizados por Gallego (2014), que defende a hipótese de uma certa "benevolência" do sistema penal uruguaio com as mulheres, restringindo o encarceramento.

O modo como as MSE são representadas pelas adolescentes, remete-nos a constatar que é inegável que houve avanço na execução das medidas, a partir da promulgação do ECA e o advento do SINASE, conforme observamos nos serviços pesquisados, mas ainda se faz necessário evoluir na gestão das MSE no Estado do Espírito Santo, tanto na Internação quanto na LA, a fim de garantir os direitos humanos para aquelas que estiveram em conflito com a lei.

O preconceito contra adolescentes que cometeram atos infracionais também é algo a ser revisto pela sociedade brasileira. Por mais sociopedagógica que seja a execução de uma MSE, esta não se tornará eficaz se nos outros âmbitos da vida das adolescentes (família, escola, comunidade em geral) elas continuarem sendo vistas como "bandidas irrecuperáveis", sem a possibilidade de colocar em prática aquilo que refletiram no desenvolvimento do processo socioeducativo. 


\section{Referências}

Abric, J. C. (2001). Las representaciones sociales: aspectos teóricos. In J. C. Abric (Org.). Prácticas Sociales y Representaciones (pp. 11-31). México: Coyoácan.

Agliardi, D. A. (2007). Histórias de vida de adolescentes com adolescentes privados de liberdade: como narram a si mesmos e aos outros. Dissertação de mestrado, Universidade Federal do Rio Grande do Sul, Porto Alegre, RS, Brasil.

Almeida, V. C. T. G. (2007). Adolescentes autoras de ato infracional: discurso, identidade e representações. Dissertação de Mestrado, Universidade Federal do Mato Grosso do Sul, Campo Grande, MS, Brasil.

Aranzedo, A. C., \& Souza, L. (2007). Adolescentes autores de homicídio: vivência da privação de liberdade e planos para o futuro. Revista Electrónica de Psicología Política, 5(15), sem paginação.

Barcinski, M. (2009). Centralidade de gênero no processo de construção da identidade de mulheres envolvidas na rede do tráfico de drogas. Ciência \& Saúde Coletiva, 14(5), 1843-1853.

Bardin, L. (1977). Análise de Conteúdo. Lisboa: Edições.

Braunstein, H. R. (2007). Mulher encarcerada: trajetória entre a indignação e o sofrimento por atos de humilhação e violência. Dissertação de Mestrado, Universidade de São Paulo, São Paulo, SP, Brasil.

Brito, L. M. T. (2007). Liberdade Assistida no Horizonte da Doutrina de Proteção Integral. Psicologia: Teoria e Pesquisa, 23(2), 133-138.

Cabral, S. H. (2003). Adolescentes em liberdade assistida: uma análise psicossocial. Dissertação de Mestrado, Universidade Católica de Goiás, Goiânia, GO, Brasil.

Carvalho, M. L., Valente, J. G., Assis, S. G., \& Vasconcelos, A. G. G. (2006). Perfil dos internos do sistema prisional do Rio de Janeiro: especificidades de gênero no processo de exclusão social. Ciência \& Saúde Coletiva, 11(2), 1461-471.

Coelho, B. I., \& Rosa, E. M. (2013). Ato infracional e medida socioeducativa: representações de adolescentes em L. A. Psicologia \& Sociedade, 25(1), 163-173.

Conselho Nacional dos Direitos da Criança e do Adolescente (2006). Sistema Nacional de Atendimento Socioeducativo. Brasília: CONANDA.

Conselho Nacional de Justiça (2013). CNJ propõe o fechamento de unidades de internação de jovens em cinco unidades da Federação. Recuperado de http://www.cnj.jus.br/noticias/cnj/60489-cnj-propoe-ofechamento-de-unidades-de-internacao-de-jovens-em-cinco-unidades-da-federacao.

Costa, A. C. G. (2006). Adolescência, risco e delito. In Por uma Política Nacional de Execução de Medidas Socioeducativas (pp. 22-28). Brasília: Secretaria Especial de Direitos Humanos. REVER

Dell'aglio, D. D., Santos, S. S., \& Borges, J. L. (2004). Infração Juvenil Feminina: Uma Trajetória de Abandonos. Interação em Psicologia, 8, 191-198.

Fachinettto, R. F. (2008). A "casa de bonecas": um estudo de caso sobre a unidade de atendimento socioeducativo feminino de RS. Dissertação de Mestrado, Universidade Federal do Rio Grande do Sul, Porto Alegre, RS, Brasil.

Feffermann, M. (2006). Vidas arriscadas. O cotidiano dos jovens trabalhadores do tráfico. Petrópolis, RJ: Vozes.

Ferreira, L. A. M. (2006). Execução das medidas socioeducativas em meio aberto: Prestação de Serviço à Comunidade e Liberdade Assistida. In: ILANUD, ABMP, SEDH \& UNFPA (Orgs.). Justiça, Adolescente e Ato Infracional: Socioeducação e Responsabilização (pp. 397- 426). São Paulo, SP: ILANUD.

Flick, U. (2004). Entrevista semi-estruturada. In U. Flick. Uma Introdução à Pesquisa Qualitativa (pp. 89 -108). Porto Alegre,RS: Bookman.

Frasseto, F. A. (2006). Execução da medida socioeducativa de internação: primeiras linhas de uma crítica garantista. In ILANUD, ABMP, SEDH \& UNFPA (Orgs.). Justiça, Adolescente e Ato Infracional: Socioeducação e Responsabilização (pp. 303 - 342). São Paulo, SP: ILANUD. 
Gallego, L. L. (2014). Processo de reflexividade em um contexto de privação de liberdade de mulheres adolescentes. Psicologia \& Sociedade, 26(3), 603-612.

Gaskell, G. (2007). Entrevistas individuais e grupais. In M. W. Bauer \& G. Gaskell (Orgs.). Pesquisa Qualitativa com Texto Imagem e Som: Um manual prático (pp. 64-89). Petrópolis, RJ: Vozes.

Gomes, C. M., \& Conceição, M. I. (2014). Sentidos da trajetória de vida para adolescentes em medida de liberdade assistida. Psicologia em Estudo, 19(1), 47-58.

Ireland, T. D., \& Lucena, H. H. R. (2013). O Presídio Feminino como Espaço de Aprendizagens. Educação \& Realidade, 38(1), 113-136.

Jodelet, D. (2001). Representações sociais: um domínio em expansão. In D. Jodelet (Org.). As Representações Sociais (pp. 17-44.). Rio de Janeiro, RJ: EDUERJ.

Jovchelovitch, S. (2003). Vivendo a vida com os outros: intersubjetividade, espaço público e representações sociais. In P. A. Guareschi \& S. Jovchelovitch (Orgs.). Textos em representações sociais (pp. 63 - 85). Petrópolis, RJ: Vozes.

Lago, N. B. (2014). Mulheres na prisão: entre família, batalhas e a vida normal. Dissertação de Mestrado, Universidade de São Paulo, São Paulo, SP, Brasil.

Madureira, A. F. A. (2010). Gênero, sexualidade e processos identitários na sociedade brasileira: tradição e modernidade em conflito. In A. L. Galinkin \& G. Santos (Orgs.). Gênero e Psicologia Social (pp. 31-63). Brasília, DF: Technopolitik.

Menandro, M. C. S., Trindade, Z. A., \& Almeida, A. M. O. (2003). Representações sociais da adolescência/juventude a partir de textos jornalísticos (1968-1974 e 1996-2002). Arquivos Brasileiros de Psicologia, 55(1), 42-55.

Monteiro, E. M. L. M., Nascimento, C. A. D., Almeida Filho, A. J. de, Araújo, A. K. de A., Carmo, D. R. B. do, \& Gomes, I. M. B. (2011). Percepção de adolescentes infratoras submetidas à ação socioeducativa sobre assistência à saúde. Escola Anna Nery Revista de Enfermagem, 15, 323 - 330.

Moscovici, S. (1978). Representação Social da Psicanálise. Rio de Janeiro, RJ: Zahar.

Moscovici, S. (2004). Representações sociais: Investigações em psicologia social. Petrópolis, RJ: Vozes.

Nardi, F. L., \& Dell'Aglio, D. D. (2012). Adolescentes em Conflito com a Lei: Percepções sobre a Família. Psic.: Teor. e Pesq., Brasília, 28(2), 181-19.

Rodrigues, T. M. S. (2002). A infindável guerra americana: Brasil, EUA e o narcotráfico no continente. São Paulo em perspectiva, 16(2), 102-111.

Sanabria, A. M., \& Rodrigues, A. F. U. (2010). Factores psicosociales de riesgo asociados a conductas problemáticas en jóvenes infractores y no infractores. Diversitas: Perspectivas em Psicología, 6(2), $257-$ 274.

Sánchez, E. A. (2002). Las Mujeres reclusas de la Cárcel Nacional de Maraqcaibo. Otras Miradas, 2(1), 38-49.

Silva, L. F. (2014). Crime, ostentação e afetividade: um estudo psicossocial sobre o adolescente em conflito com a lei. Dissertação de Mestrado, Pontifícia Universidade Católica de São Paulo, São Paulo, SP, Brasil.

Souza, K. O. J. de. (2009). A pouca visibilidade da mulher brasileira no tráfico de drogas. Psicologia em Estudo, 14(4), 649-657.

Zappe, J. G., \& Dias, A. C. G. (2012). Violência e fragilidades nas relações familiares: refletindo sobre a situação de adolescentes em conflito com a lei. Estudos de Psicologia, 17(3), 389-395.

Zappe, J. G., \& Ramos, N. V. (2010). Perfil de adolescentes privados de liberdade em Santa Maria/RS. Psicologia \& Sociedade, $22(2), 365-373$. 